\title{
INFLUÊNCIA DO DIFUSOR DE ARGÔNIO NA LIMPIDEZ DO AÇO DURANTE O PROCESSO DE LINGOTAMENTO CONTÍNUO*
}

\section{Resumo}

Isabella Rissari da Silva Lana ${ }^{1}$ Taís Fernandes de Oliveira ${ }^{2}$

Os primeiros instantes da fabricação de aço são extremamente importantes no que se diz respeito á qualidade superficial e interna do produto. No processo de lingotamento contínuo em uma Aciaria, existe o distribuidor, este a princípio exercia apenas a função de reservatório intermediário do aço líquido, ficando entre a panela e o molde, distribuindo o fluxo aos veios para que se tenha uma solidificação mais controlada. Atualmente o distribuidor exerce outras funções, como a melhoria na limpidez do aço. Um dos mecanismos utilizados para que haja essa melhoria no distribuidor, é o difusor de argônio. Este mecanismo ocorre através de uma cortina de gás inerte com capacidade de flotação de inclusões de classificações endógenas e/ou exógenas. Esse trabalho tem como objetivo testar e comparar o desenvolvimento do difusor de argônio e identificar sua eficiência na limpidez do aço. A técnica adotada para determinação da eficácia do difusor foi através da retirada de amostras no distribuidor e molde durante o processo de lingotamento contínuo, essas amostras foram analisadas no laboratório para que fosse determinada através de métodos indiretos, a medição de alumínio total. Constatou-se que os tipos de aço usados nos testes, tem capacidade de chegar ao lingotamento contínuo já com altos teores de limpidez, mas, mesmo assim, a quantidade de inclusões de alumina observada no molde apresentase bem mais baixa no veio com difusor de argônio.

Palavras-chave: Lingotamento contínuo; Difusor de argônio; Limpidez do aço.

\section{Abstract}

\section{CONTINUOUS CASTING, ARGON DIFFUSER AND STEEL CLARITY}

The first moments of the steel manufacturing is extremely important as concerns the superficial and inner quality of the product. In the process of continuous casting in a Steelmaking, there is the tundish, who only held the intermediate reservoir function of the liquid steel, getting between the pot and the die, distributing the flow to the beams in order to have a more controlled solidification. Currently the tundish performs other functions, such as improvement in the steel clarity. One of the mechanisms used so there is the improvement in tundish, is argon diffuser. This mechanism uses an inert gas curtain flotation ability to indigenous ratings inclusions and / or exogenous. This work aims to test and compare the development of argon diffuser and identify their efficiency in the steel clarity. The technique used to determine the effectiveness of the diffuser was by withdrawing samples at the tundish and mold during the continuous casting process, the samples were analyzed in the laboratory to be determined by indirect methods to measure total aluminum. It was found that the types of steel used in the tests is capable of continuous casting to reach the already high levels of purity, but even so, the amount of alumina inclusions observed is presented in the mold and lower the shaft with diffuser argon.

Keywords: Continuous casting; Argon diffuser; Steel clarity.

1 Estudante de Engenharia Metalúrgica, Centro Universitário do Leste de Minas Gerais (UNILESTEMG), Timóteo, MG, Brasil.

2 Engenheira Metalúrgica, UNILESTE-MG, Coronel Fabriciano, MG, Brasil. 


\section{INTRODUÇÃO}

\subsection{Contextualização do Tema}

Atualmente o aço é um dos materiais mais utilizados no mundo, mas para que mantenha competitividade aos novos materiais, a engenharia busca tecnologias que promovem melhorias nos seus processos e na qualidade de seus produtos. Uma das formas de melhoria é o controle do escoamento do aço líquido na panela, no distribuidor e no molde de lingotamento contínuo, obtendo-se, assim uma maior limpidez do metal produzido.

No lingotamento contínuo do aço, o distribuidor funciona como um reservatório intermediário entre a panela e o molde, com função de regular o fluxo do metal, distribuir e abastecer o molde de aço líquido, numa taxa constante e de forma que se mantenha a continuidade do processo de lingotamento.

Segundo ANDRADE [1] nos últimos anos, com uma grande busca do mercado por aços de alta qualidade interna e superficial, o distribuidor passou a ser considerado um reator metalúrgico, ao invés de servir apenas como reservatório de aço líquido. Assim o distribuidor atual é projetado de forma a possibilitar também a realização de operações metalúrgicas, tais como controle do superaquecimento, de desoxidar o aço, manter a homogeneidade térmica e química entre os veios, separação e flotação de inclusões não metálicas.

A qualidade do aço é caracterizada pelo seu grau de limpidez, que por sua vez é proporcional à quantidade, à morfologia e à distribuição de diferentes tamanhos de inclusões não metálicas presentes no mesmo. De acordo com ZHAN [2], a limpeza do aço não envolve apenas o controle do conteúdo de inclusões no aço, mas também evita a presença de inclusões maiores que o tamanho crítico prejudicial ao produto.

Em particular, a limpeza do aço líquido no distribuidor desempenha um papel importante na melhoria da qualidade final do mesmo, bem como na prevenção da obstrução da válvula submersa. Segundo TANAKA [3] é possível realizar no distribuidor a flotação e a remoção de inclusões, no entanto, contaminações do aço também estão sujeitas a acontecer, devido ao arraste de escória da panela para o distribuidor, à oxidação do banho metálico e à dissolução do refratário. Pensando nisso, técnicas para limpeza, prevenção ou redução da contaminação dos aços estão sendo desenvolvidas.

Uma das possíveis maneiras de controlar ou reduzir o conteúdo de inclusões no aço lingotado continuamente seria a injeção de gases inertes pelo fundo do distribuidor. Os gases injetados modificam o padrão de fluxo existente no interior do distribuidor, capturando e arrastando as inclusões dispersas no aço até a camada de escória de cobertura, como representado na figura 1.
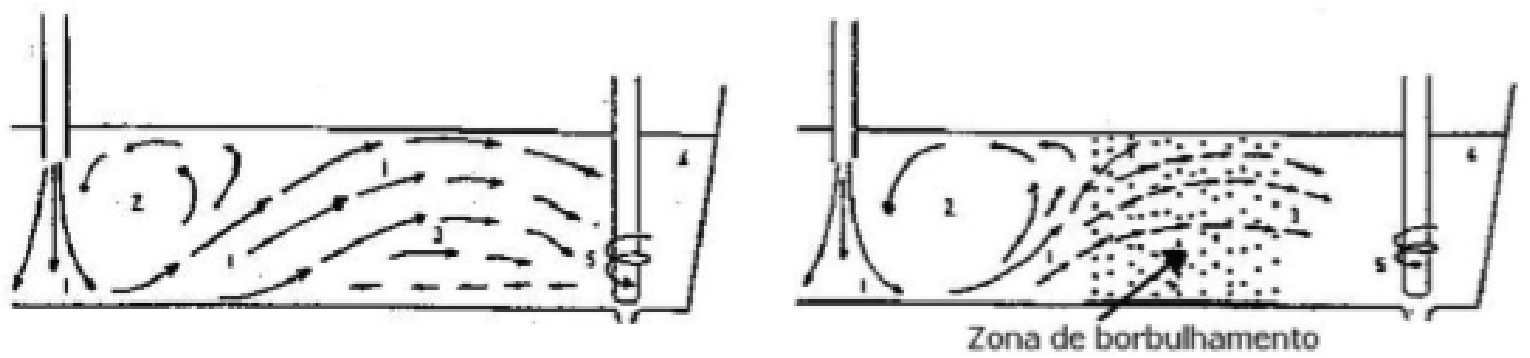

Figura 1 - Esquema da cortina de gás borbulhado no fundo do distribuidor. Fonte: THOMAS (2003) 


\subsection{Objetivo Geral}

Obter resultados da influência do difusor de argônio na limpidez do aço durante o processo de lingotamento contínuo.

\subsubsection{Objetivo Específico}

- Efetuar uma revisão bibliográfica do processo de lingotamento contínuo de aços, que diz respeito á injeção de argônio pelo fundo do distribuidor, com a intenção de melhorar a qualidade do produto final.

- Investigar em campo a eficiência deste gás inerte para flotação de inclusões, atrelado na melhoria da qualidade superficial e interna de placas.

- Minimizar o acúmulo de alumina no tampão e válvulas submersas, na melhoria da lingotabilidade e na redução de recusa por esfoliamento em produtos tiras.

\subsection{Revisão Bibliográfica}

\subsubsection{Lingotamento contínuo}

O processo de lingotamento contínuo consiste basicamente em três reatores metalúrgicos: panela, o distribuidor e o molde.

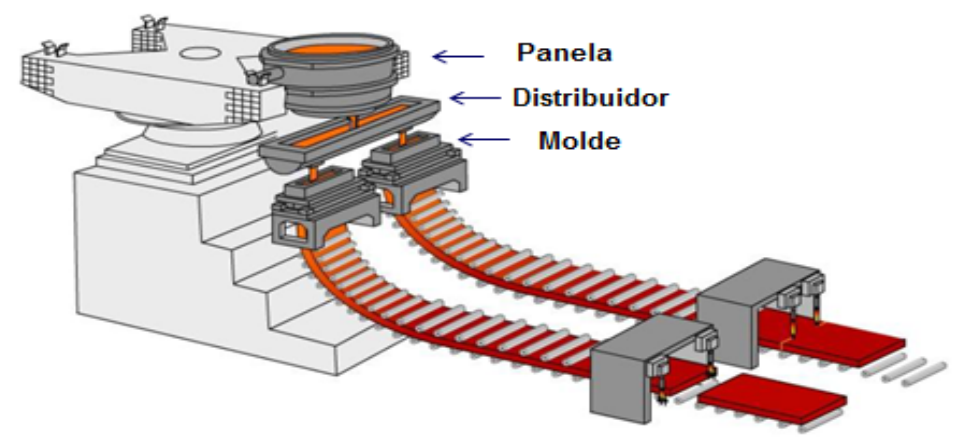

Figura 2 - Representação da maquina de lingotamento contínuo. Fonte: Usiminas (2014)

\subsubsection{Difusor de argônio}

Difusor de argônio (TGD - TundishGasDiffuser) é uma peça de refratário poroso usada na base do distribuidor. Nesta peça é feita a injeção de argônio de alta pureza. A função do argônio é criar uma cortina de gás inerte que irá captar as inclusões não metálicas, principalmente a alumina.

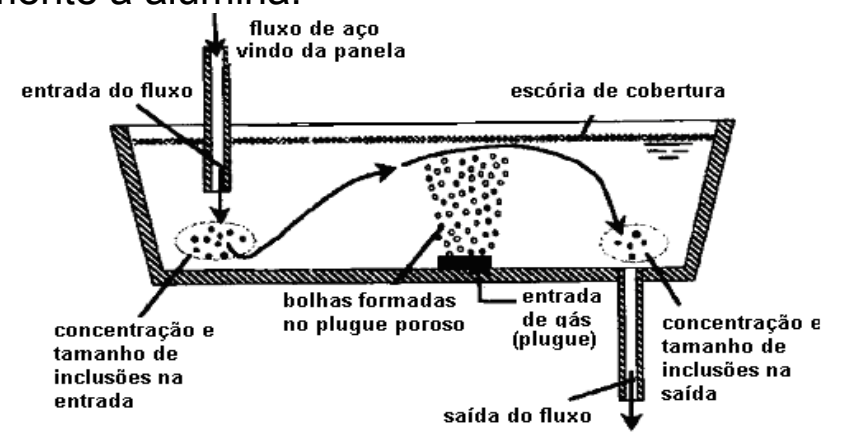

Figura 3 - Representação esquemática do distribuidor simples, equipado apenas com difusor de argônio para a remoção de inclusões. Fonte: ROGLER (2004) 


\subsubsection{Funções do difusor de argônio}

- Melhoria da qualidade interna da placa;

- Menor presença de alumina.

- Minimização da obstrução de válvulas submersas;

- Menor presença de alumina e menor geração de clogging.

- Manutenção da lingotabilidade e melhoria do controle de nível no molde;

- Menor necessidade de batida de tampão.

- Minimização da recusa por esfoliamento em produtos tiras.

- Menor presença de alumina nas placas lingotadas.

\subsubsection{Flotação e separação de inclusões}

O processo de arraste de uma inclusão por uma bolha de gás no interior de aço líquido:

ROGLER [4] demonstra que primeiramente a inclusão se aproxima da bolha de gás, a camada entre a partícula e a bolha se torna menor que a espessura crítica durante o contato, essa camada irá se romper fazendo a inclusão se aderir à superfície da bolha.

- $\theta_{\mathrm{A}}$ : Ângulo crítico de fixação - Partícula com ângulo $<\theta_{\mathrm{A}}$, irá colidir e aderir à bolha;

- $\theta_{C}$ : Ângulo de colisão - Partícula com ângulo $>\theta_{A} \mathrm{e}<\theta_{c}$, irá colidir com a bolha, sem se aderir.

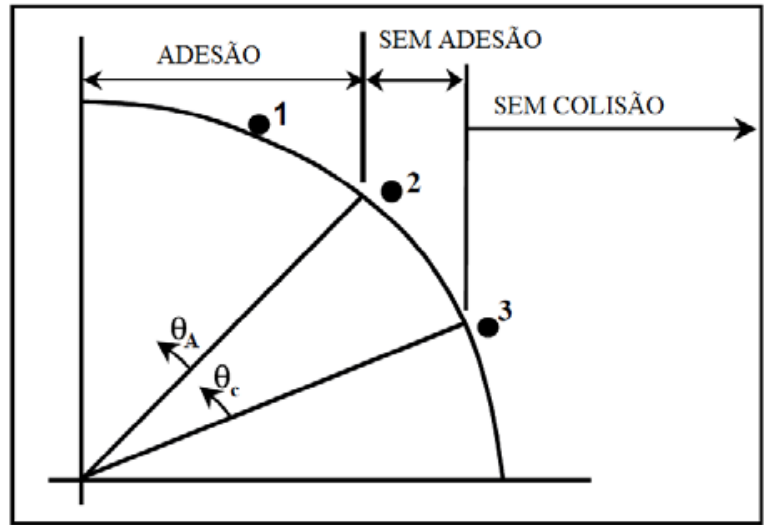

Figura 4 - Esquema representando os ângulos críticos. Fonte: ROGLER (2004)

\section{MATERIAIS E MÉTODOS}

\subsection{Montagem do Difusor de Argônio}

A VESUVIUS [5] apresenta o difusor de argônio ou (TGD - TundishGasDiffuser) como um equipamento que ajuda a reduzir as zonas "mortas" e as diferenças de temperaturas no interior do distribuidor. A vazão controlada de microbolhas de argônio em toda a largura do distribuiro irá remover as inclusões de forma muito eficaz.

O TGD normalmente é colocado no fundo do distribuidor e opera com uma vazão de argônio controlada e de alta pureza. Ele é de material refratário poroso para que a saída do gás inerte seja possível.

As posições de instalação do TGD no distribuidor foram sugeridas pelo fabricante, após análise dos resultados obtidos em seus modelamentos matemáticos. 


\subsection{Princípios Básicos de Operação}

Foram utilizados dois TGD's Vesuvius de $500 \mathrm{~mm}$, sendo um para cada distribuidor com dois veios cada. A máquina de lingotar foi a mesma, foram permutados apenas os distribuidores. Para um dos distribuidores (teste 1) o aço processado foi o ASTMA572-50-1 (aço estrutural microligado da classe de resistência de $500 \mathrm{MPa}$ ) e para ou outro distribuidor (teste 2) o aço processado foi o ASTM A 36 (aço estrutural da classe de resistência $400 \mathrm{MPa}$ ), na tabela 1 é possível ver as composições dos aços testados.

Tabela 1 - Composições Químicas obtidas (\% em massa)

\begin{tabular}{lccccccccc}
\hline \multicolumn{1}{c}{ Corrida } & $\mathbf{C}$ & $\mathbf{M n}$ & $\mathbf{S i}$ & $\mathbf{P}$ & $\mathbf{S}$ & $\mathbf{A l}$ & $\mathbf{C a}$ & $\mathbf{N b}$ & $\mathbf{T i}$ \\
\hline Teste 1 - 494914 & 0,19 & 1,47 & 0,33 & 0,021 & 0,001 & 0,031 & 0,0012 & 0,037 & 0,027 \\
ASTM A 572 50 1 & & & & & & & & & \\
\hline Teste 2 - 598764 & 0,14 & 0,70 & 0,17 & 0,013 & 0,008 & 0,039 & 0,0002 & 0,001 & 0,001 \\
\hline ASTM A 36 & & &
\end{tabular}

O aço ASTM A 572501 microligado ao Nb e Ti teve adição de Ca para controle das formas das inclusões além de apresentar enxofre bem inferior que o da corrida do aço ASTM A 36 que não teve adição de Ca e que não tem microligas.

\subsection{Procedimento do Teste}

Durante esse teste observou-se as vazões de argônio durante o processo de lingotamento contínuo, isso é fundamental para o estudo, pois se houver uma vazão maior do que a necessária combinada com a turbulência do banho pode ocorrer o arraste de escória para o aço. Foram retiradas no total 15 amostras do aço líquido em cada teste, sendo 9 amostras no distribuidor e 6 nos moldes, sendo 5 do total retiradas no início do lingotamento (panela com 120t), 5 retiradas no meio (panela com 90t) e 5 no fim (panela com 45t) os locais são mostrados na figura 5.Os operadores utilizaram a prática de retirada de amostras pirulitos com cabo de $80 \mathrm{~mm}$.

Os locais de amostragem terão nomenclaturas da seguinte forma:

-D 1: no distribuidor na região do tampão no veio ímpar.

-D 2: no distribuidor no veio par ao lado da válvula longa.

-D 3: no distribuidor no veio par ao lado do tampão.

- M 1: no molde, lado oposto ao scan, veio ímpar.

-M 2: no molde, lado oposto ao scan, veio par.

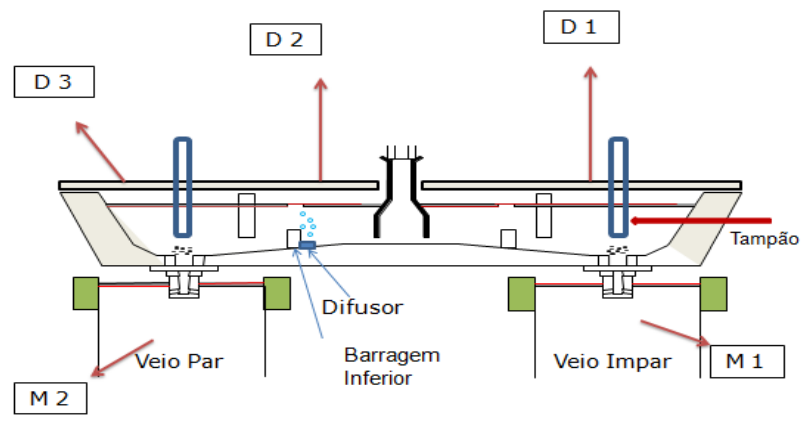

Figura 5 - Local de retirada das amostras no distribuidor e molde, início meio e fim do lingotamento, para cada teste. Fonte: Autoras (2014) 


\subsection{Métodos de Avaliação}

Devido ao alto custo, grande tempo requerido e dificuldades de amostragem dos métodos diretos, geralmente, a avaliação da limpidez do aço é realizada nas indústrias através de métodos indiretos como alumínio total.

\subsubsection{Medição do alumínio total (T.A.)}

O alumínio total é a soma do alumínio solúvel no aço combinado com alumínio na forma de inclusão não metálica, ou seja, a alumina. Para encontrar o alumínio solúvel a amostra do aço líquido é preparada via úmida para medição por espectrometria de emissão óptica (plasma acoplado indutivamente). Essa análise possui uma margem de erro de $2 \mathrm{ppm}$.

O alumínio total é medido em amostras de aço, que através de uma queima são medidos o teor via espectrometria de emissão óptica dos precipitados.

A quantidade de alumínio em forma de inclusão foi determinada através da seguinte fórmula.

$$
\text { Al Total }- \text { Al Solúvel }=\text { Al Inclusão }
$$

\subsubsection{Equipamentos utilizados para análise}

- Leco

- Espectrômetro por emissão ótica

- Espectrômetro de Plasma

- Celox

\section{RESULTADOS E DISCUSSÃO}

\subsection{Análise do Alumínio}

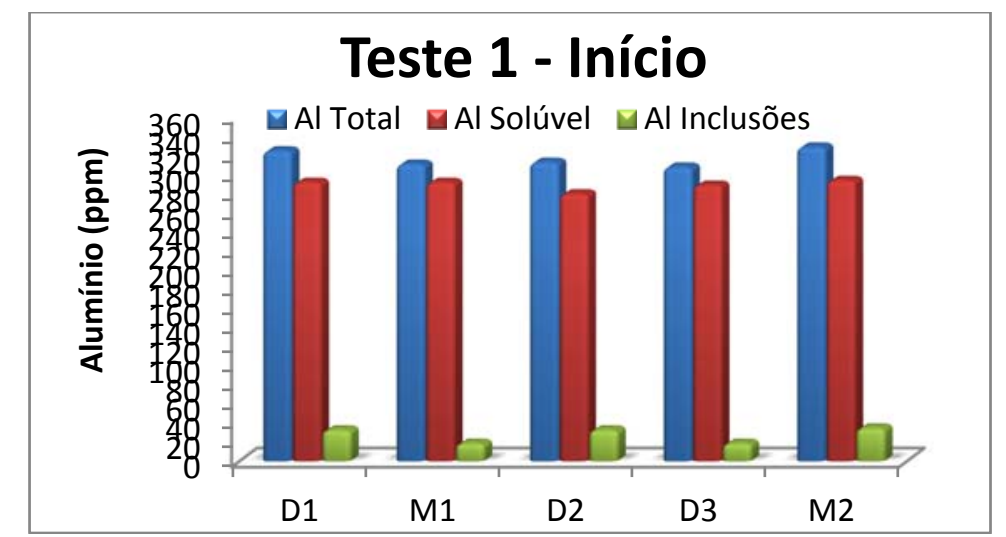

Figura 6 - Análise de Alumínio (Total, Solúvel, Inclusões), Teste 1. 


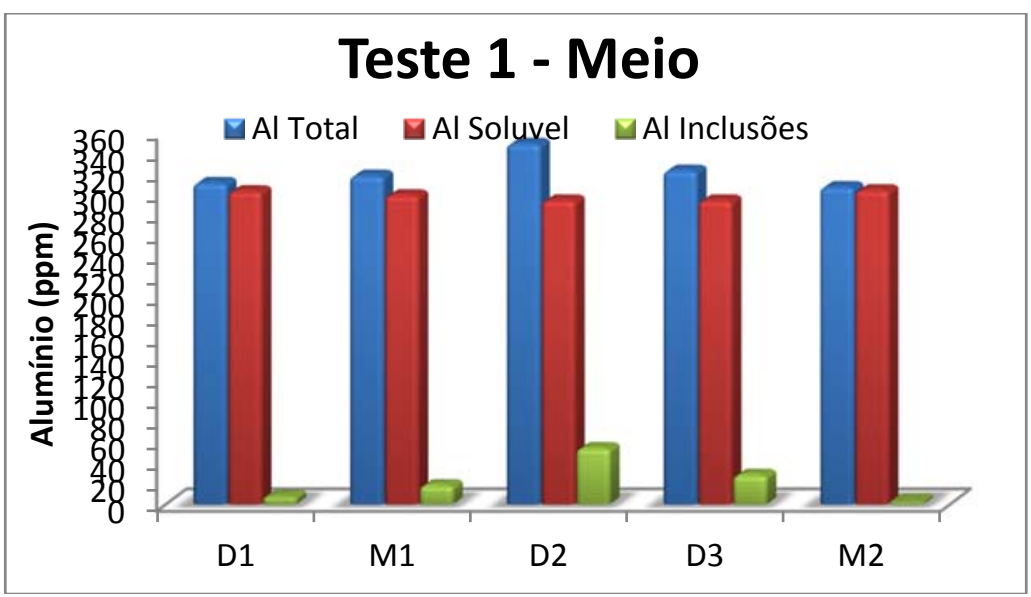

Figura 7 - Análise de Alumínio (Total, Solúvel, Inclusões), Teste 1

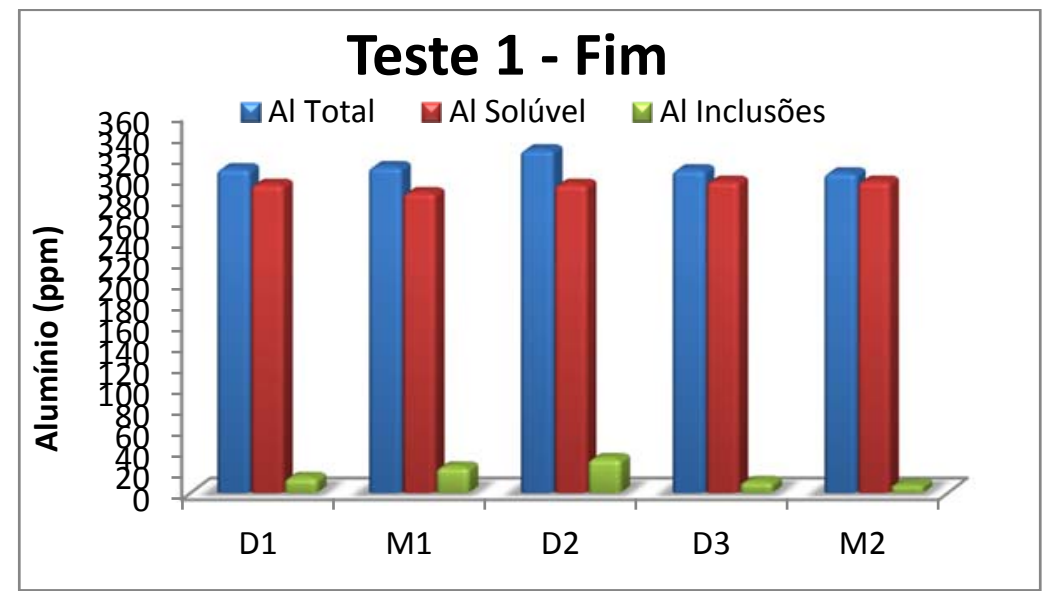

Figura 8 - Análise de Alumínio (Total, Solúvel, Inclusões), Teste 1.

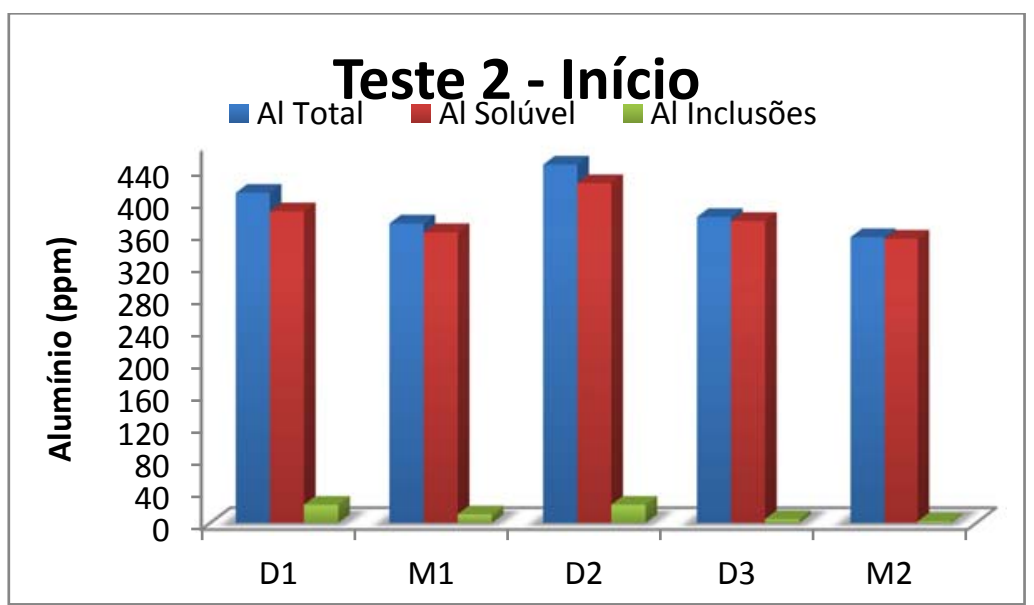

Figura 9 - Análise de Alumínio (Total, Solúvel, Inclusões), Teste 2. 


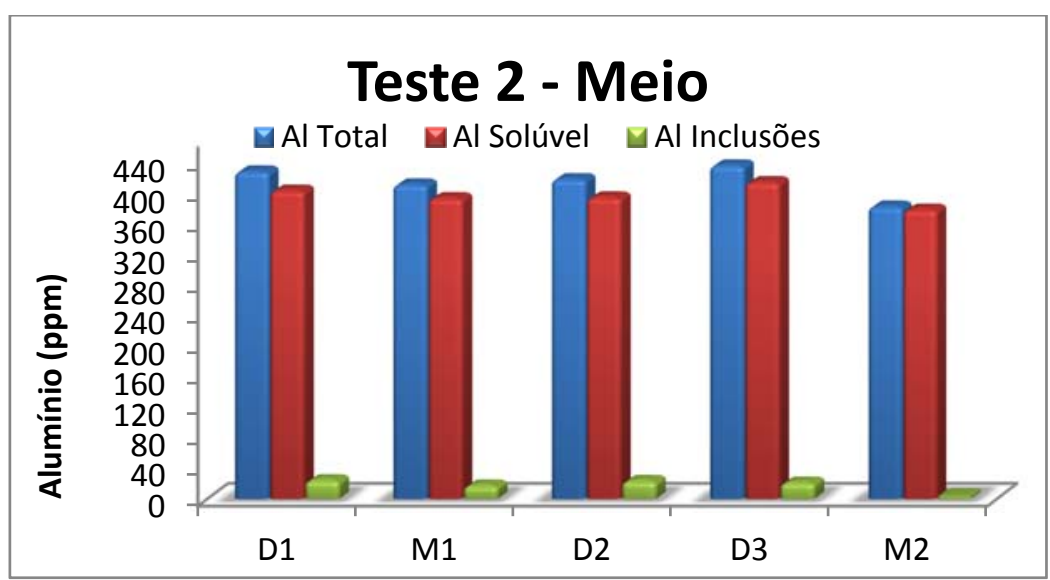

Figura 10 - Análise de Alumínio (Total, Solúvel, Inclusões), Teste 2.

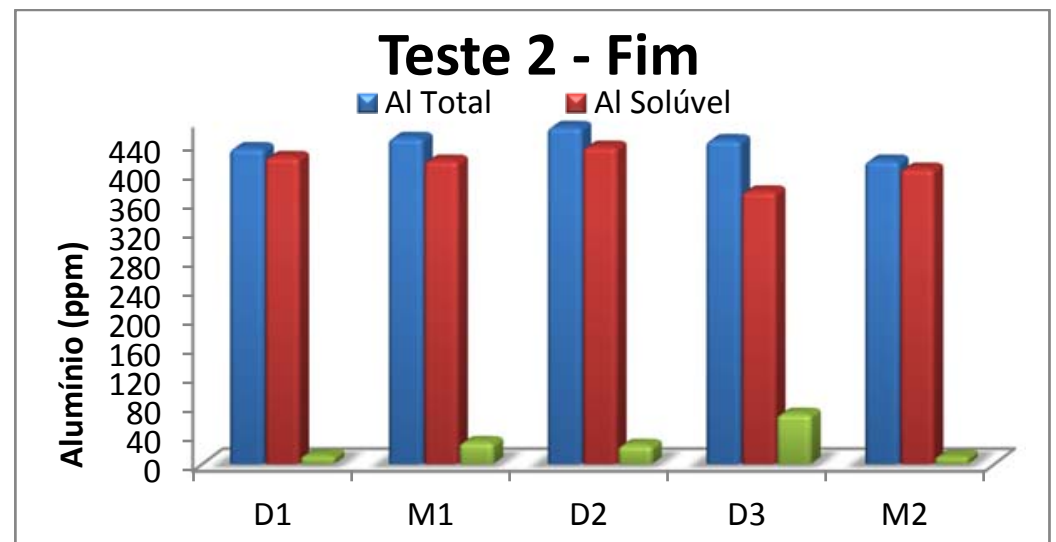

Figura 11 - Análise de Alumínio (Total, Solúvel, Inclusões), Teste 2.

\subsection{Análise Metalográfica}

Para que se tenha uma análise mais refinada, foi conferida a limpidez do aço nos dois veios através do microscópio óptico. Em função da estabilidade do processo, as amostras analisadas foram apenas do teste 2, retiradas no início do lingotamento, especificamente nos moldes.

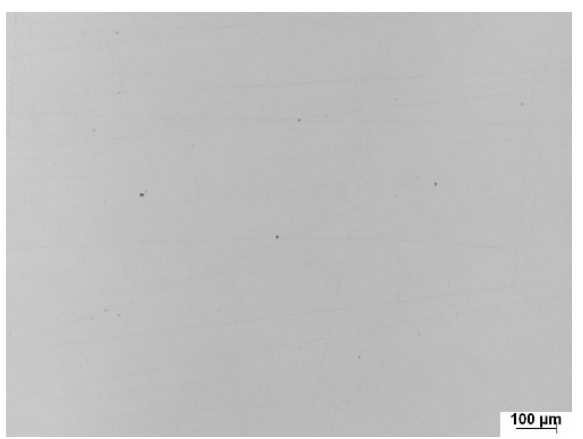

Figura 12 - Teste 2, Veio c/TGD - Aumento de 100X 
$100 \mu \mathrm{m}$

Figura 13 - Teste 2, Veio s/TGD - Aumento de 100X

Tabela 2 - Carta Padrão ASTM E 45 - I, (Quantidade e espessura de Inclusão).

\begin{tabular}{|c|c|c|c|}
\hline Sulfetos & Alumina & Silicatos & Oxido \\
\hline $0,0 \mathrm{~F}$ & $0,0 \mathrm{~F}$ & $0,0 \mathrm{~F}$ & $0,5 \mathrm{~F}$ \\
\hline $0,000 \mathrm{G}$ & $0,000 \mathrm{G}$ & $0,000 \mathrm{G}$ & \\
\hline
\end{tabular}

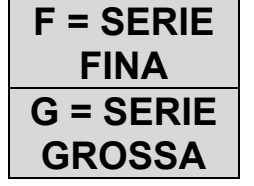

Tabela 3 - Carta Padrão Complementar, ASTM E 45 - II, (Tamanho de Inclusão).

\begin{tabular}{|c|c|}
\hline Sulfeto & Oxido \\
\hline 1 & 1 \\
\hline
\end{tabular}

Feito a metalografia foi possível verificar pelas figuras 12, 13 e tabelas de comparação com as cartas padrão ASTM, uma alta limpidez neste aço tratado. Os dois veios, com e sem difusor de argônio apresentaram poucas inclusões de tamanhos bem pequenos.

\section{CONCLUSÃO}

Devido a alta limpidez dos aços das duas corridas consideradas (teste 1 e 2), foi difícil perceber a influência do difusor de argônio. O pequeno número de dados agravou ainda mais a percepção desta influência. Porém, mesmo estando com alta limpidez as duas corridas, a quantidade de inclusões de alumina observada no molde apresenta-se bem mais baixa no veio com difusor de argônio, permitindo assim concluir sua eficiência na redução de óxidos de alumínio como era esperado.

\section{Agradecimentos}

A Usiminas e ao Centro Universitário do Leste de Minas Gerais 


\section{REFERÊNCIAS}

1 ANDRADE, S. O.C. E BARBOSA, F. A., Escoamento do aço liquido. Lingotamento continuo de placas, 2011. p.34-64.

2 ZHAN, L. Modelling of Fluid Flow in Tundish with Gas Bubblin. 2009. Qian'An Iron \& Steel Co

3 TANAKA, H., NISHIHARA, R., KITAGAWA, I., E TSUJINO, R. Quantitative analysis of contamination of molten steel in tundish. ISIJ International, Vol. 33, (1993), p. 12381243.

4 ROGLER, J. P. Modeling of Inclusion Removal in a Tundish by Gas Bubbling. 2001. 78p. Dissertação, Mestrado em Engenharia Química - RyersonUniversity. Toronto, Ontario, Canada, 2004.

5 Vesuvius. Disponível em: <http://www.vesuvius.com/en/end-markets/ironsteel/casting/continuous-casting/tundish-furniture/diffusers/> Acessado em outubro de 2014. 